\title{
Economic comparison of reproductive programs for dairy herds using estrus detection, timed artificial insemination, or a combination
}

\author{
K. N. Galvão, ${ }^{\star 1}$ P. Federico,† A. De Vries, $\ddagger$ and G. M. Schuenemann§ \\ *Department of Large Animal Clinical Sciences and D. H. Barron Reproductive and Perinatal Biology Research Program, University of Florida, \\ Gainesville 32610 \\ †Department of Mathematics, Computer Science and Physics, Capital University, Columbus, $\mathrm{OH} 43210$ \\ $\ddagger$ Department of Animal Sciences, University of Florida, Gainesville 32610 \\ $\S$ Department of Veterinary Preventive Medicine, The Ohio State University, Columbus 43210
}

\section{ABSTRACT}

The objective of this study was to compare the economic outcome of reproductive programs using estrus detection (ED), timed artificial insemination (TAI), or a combination of both (TAI-ED) using a stochastic dynamic Monte-Carlo simulation model. Programs evaluated were (1) ED only; (2) TAI: Presynch-Ovsynch for first AI, and Ovsynch for resynchronization of open cows at 32 d after AI; (3) TAI-ED: Presynch-Ovsynch for first AI, but cows underwent ED and AI after first $\mathrm{AI}$, and cows diagnosed open $32 \mathrm{~d}$ after AI were resynchronized using Ovsynch. Evaluated were the effect of ED rate (40 vs. $60 \%$; ED40 or ED60), accuracy of estrus detection (85 vs. 95\%), compliance with the timed AI protocol (85 vs. $95 \%$ ), and milk price ( $\$ 0.33$ vs. 0.44 / $\mathrm{kg}$ ). Conception rate to first service was set at $33.9 \%$ and then decreased by $2.6 \%$ for every subsequent service. Abortion was set at $11.3 \%$. Cows were not AI after $366 \mathrm{~d}$ in milk, and open cows were culled after $450 \mathrm{~d}$ in milk. Culled cows were immediately replaced. Herd size was maintained at 1,000 cows, and the model accounted for all incomes and costs. Simulation was performed until steady state was reached $(3,000 \mathrm{~d})$, and then average daily values for the subsequent 2,000 d were used to calculate profit/cow per year. Net daily value was calculated by subtracting the costs (replacement, feeding, breeding, and other costs) from the daily income (milk sales, cow sales, and calf sales). The ED40 models resulted in greater profits than the TAI- 85 model but lower profits than the TAI-95 model. Both ED60 models resulted in greater profits than the TAI-95 model. Combining TAI and ED increased profits within each level of accuracy or compliance. Adding TAI to ED would increase overall profit/cow per year by $\$ 46.8$ to $\$ 74.7$ with $40 \% \mathrm{ED}$, and by $\$ 8.9$ to $\$ 30.5$ with $60 \%$ ED. Adding ED to TAI would increase profit/cow per year

Received July 25, 2012.

Accepted December 9, 2012.

${ }^{1}$ Corresponding author: galvaok@ufl.edu by $\$ 64.2$ to $\$ 99.4$ with $85 \%$ compliance and by $\$ 31.8$ to $\$ 59.7$ with $95 \%$ compliance. Although combining TAI and ED increased profits within each level of accuracy or compliance, when evaluated separately, ED60 with $95 \%$ accuracy or TAI with $95 \%$ compliance were as profitable as or more profitable than TAI-ED with low ED, accuracy, or compliance. Therefore, producers can improve their profits by combining TAI and ED as reproductive management; however, if a herd can achieve high ED with high accuracy or have high compliance with injections, using only ED or TAI might be more profitable than trying to do both.

Key words: economics, reproductive program, dairy cow

\section{INTRODUCTION}

Reproductive performance is a key determinant of dairy cow profitability (Britt, 1985, Meadows et al., 2005, De Vries, 2006; De Vries et al., 2006). Several parameters affect reproductive performance, such as voluntary waiting period (VWP), service rate (SR), conception rate (CR), and pregnancy loss. Pregnancy rate (PR) is the combination of SR and CR, and is believed to be one of the most comprehensive measures of reproductive performance. Depending on the dairy, one or more of these factors may be a problem. Traditionally, at the end of the VWP, cows would be AI upon detection of estrus, and cows not AI up to a predetermined DIM would be presented for veterinary evaluation and treated according to findings in the ovaries or uterus. Artificial insemination upon natural estrus is still the main method to breed cows (54.7 and 39.6\% for first and subsequent services, respectively; USDA, 2009); however, with the advent of synchronization of ovulation for timed AI (Pursley et al., 1995, Moreira et al., 2001), dairies are increasingly adopting these protocols as part of their reproductive programs (Caraviello et al., 2006; USDA, 2009). For the most part, synchronization protocols are used in combination with estrus detection (Caraviello et al., 2006; USDA, 2009). 
Nonetheless, in an attempt to tightly control SR and to eliminate the need for estrus detection, many herds (9.9 to $13.2 \%$ for first and subsequent services, respectively) are opting for the use of timed AI exclusively (USDA, 2009; Giordano et al., 2011).

Although several studies have evaluated CR and time to conception using different reproductive programs (Pursley et al., 1997a; Cerri et al., 2004; Tenhagen et al., 2004), very few have evaluated the economic benefits of using such programs (Tenhagen et al., 2004; Giordano et al., 2011). Because of the wide variation in factors that affect reproductive efficiency of a given program such as SR, accuracy of estrus detection, and compliance with the timed AI (TAI) protocol, simulation models are an attractive option to evaluate different scenarios (Inchaisri et al., 2010). Stochastic dynamic dairy herd simulation models have been used to evaluate the economic benefit of different treatments for cystic ovarian disease (De Vries et al., 2006). Similar models could be used to compare the economic benefit of different reproductive programs in different scenarios (Marsh et al., 1985; Sørensen et al., 1992; Plaizier et al., 1997). To our knowledge, only one study has evaluated the economics of combining ED and TAI, although using a deterministic model (Giordano et al., 2011). Therefore, the objective of this study was to compare the economic benefits of different reproductive programs that use ED only, TAI only, or a combination of both (ED-TAI) using a stochastic dynamic simulation model. Of particular interest was the effect of SR (40 vs. $60 \%$ ), accuracy of ED (85 vs. 95\%), compliance with the timed AI protocol ( 85 vs. $95 \%$ ), and milk price $(\$ 0.33$ vs. $0.44 / \mathrm{kg})$.

\section{MATERIALS AND METHODS}

\section{Simulation Model}

An individual-based model of a dairy herd was developed to evaluate the technical and economic performance of different reproductive programs that use ED, TAI, or ED-TAI. The model tracks the daily reproductive status and milk production of each cow in the herd subject to a given reproductive protocol and a sequence of events including estrus, estrus detection, insemination, diagnostics, and calving. Stochastic elements were incorporated in the occurrence and detection of estrus, success of AI, occurrence of pregnancy loss, occurrence of involuntary culling, and occurrence of death. The model was implemented in the freeware agent-based modeling environment Netlogo (Wilensky, 1999; http://ccl.northwestern.edu/netlogo). The model structure and order of events are summarized in the Appendix in the form of pseudo-code.

\section{Reproductive Parameters and Programs}

The reproductive parameters were modeled as a sequence of discrete events, each with their own probability, timing, and outcome. The parameters evaluated were estrus occurrence, estrus detection, AI, conception, pregnancy loss, and calving. The reproductive programs evaluated were as follows: $\mathrm{ED}=\mathrm{AI}$ upon estrus detection; TAI $=$ first AI after a PresynchOvsynch protocol (Pursley et al., 1995; Moreira et al., 2001), and subsequent AI after an Ovsynch protocol; TAI-ED = first AI after a Presynch-Ovsynch protocol, and subsequent AI upon estrus detection, or TAI if not AI upon estrus detection up to the scheduled day of TAI. The first estrus after calving followed a log normal distribution with mean (SD) of $19 \mathrm{~d}$ (11 d) truncated at $2 \mathrm{~d}$ (De Vries et al., 2006). The second and subsequent estruses followed a normal distribution with mean (SD) of $21 \mathrm{~d}(2.5 \mathrm{~d})$. Return to estrus after TAI also followed a normal distribution with mean (SD) of $21 \mathrm{~d}(2.5 \mathrm{~d})$. As previously reported (Giordano et al., 2011), the VWP for the ED group was set at 50 DIM; however, the VWP for the TAI and TAI-ED groups were set at 72 DIM. At the end of the VWP, all cows in the ED group were AI upon estrus detection, and all cows in the TAI and TAI-ED were timed AI for the first time. Pregnancy diagnosis was scheduled at $32 \mathrm{~d}$ after AI, and pregnant cows were reconfirmed at 91 and $200 \mathrm{~d}$ after AI. Accuracy of pregnancy diagnosis was set at $100 \%$. Conception probability for AI upon accurate estrus detection was set at $33.9 \%$ for the first $\mathrm{AI}$ and then decreased by $2.6 \%$ for every subsequent $\mathrm{AI}$ (De Vries, 2004, 2006; Norman et al., 2009; Hertl et al., 2010). Conception probability for AI upon inaccurate estrus detection was set at $6.2 \%$ of the conception probability for accurate estrus detection. This assumption was based on data from Galvão et al. (2007), Santos et al. (2010), Giordano et al. (2012a), and Ribeiro et al. (2012). In total, 2,070 cows had plasma progesterone concentrations on the day of AI; of those, 1,929 had progesterone concentration $<1 \mathrm{ng} / \mathrm{mL}$ and 141 had progesterone concentration $\geq 1 \mathrm{ng} / \mathrm{mL}$. Conception risk was $33.9 \%(654 / 1,929)$ for cows accurately AI based on progesterone concentration $(<1 \mathrm{ng} / \mathrm{mL})$, and $2.1 \%$ (3/141) for cows inaccurately AI; therefore, conception risk for inaccurate AI was $6.2 \%$ of accurate AI $(2.1 / 33.9)$. Conception probability for AI following the complete Ovsynch protocol was set at $85.6 \%$ of the conception probability for AI upon accurate estrus detection $(33.9 \% \times 0.856=29.0 \%)$. This assumption was based on data from Burke et al. (1996), Pursley et al. (1997a,b), and Tenhagen et al. (2004), where the CR for the Ovsynch protocol without presynchronization was compared with conception risk at detected estrus 
in a total of 2,891 AI. Overall, the conception risk for Ovsynch was $38.8 \%$ (633/1,631 AI) and conception risk for estrus detection was 45.3 (571/1,260 AI); therefore, the conception risk for Ovsynch was $85.6 \%$ (38.8/45.3) of the conception risk for estrus detection. Missing any injection of the Ovsynch protocol resulted in conception probability of $18.1 \%$ of a complete Ovsynch (29.0\% $\times 0.181=5.2 \%)$. This assumption was based on data from Moreira et al. (2001), Galvão et al. (2004), Galvão and Santos (2010), and Santos et al. (2010), where conception risk was evaluated based on synchrony of ovulation after the last GnRH injection of the Ovsynch protocol. In total, 1,473 cows were evaluated, and of those, 1,258 had the ovulation synchronized after the last GnRH injection and 215 did not. Conception risk was $43.6 \%$ for cows with synchronized ovulation and $7.9 \%$ for unsynchronized ovulations; therefore, conception risk for cows with unsynchronized ovulations was $18.1 \%(7.9 / 43.6)$ of the conception risk for cows with synchronized ovulations. Conception probability following a complete Presynch-Ovsynch protocol was $29.8 \%$ higher than Ovsynch alone $(29.0 \% \times 1.298=37.6 \%)$. This assumption was based on data from Moreira et al. (2001), El-Zarkouny et al. (2004), and Navanukraw et al. (2004), where the benefit from presynchronization was evaluated. In total, 1,428 cows were evaluated, and of those, 715 were presynchronized and 713 were not. Conception risk was $48.3 \%$ for presynchronized cows and $37.2 \%$ for cows not presynchronized; therefore, the conception risk was $29.8 \%$ greater $(48.3 / 37.2=1.298$ or $29.8 \%$ ) for presynchronized cows. If one of the prostaglandin injections of the Presynch protocol was missed, $50 \%$ of the benefit was lost, and if both were missed, $100 \%$ of the benefit was lost. One would assume that the second prostaglandin injection is more important than the first but, because of lack of hard data, and for simplicity, equal weight was given to each injection.

Cows diagnosed not pregnant were managed according to each reproductive program: no intervention (ED) or were started on the Ovsynch protocol for timed AI (TAI and TAI-ED). Cows were allowed to be AI up to 366 DIM and allowed to be enrolled in the Ovsynch protocol up to 356 DIM so the last TAI would occur at 366 DIM. The period of $366 \mathrm{~d}$ was chosen to allow a total of $8 \mathrm{AI}$ for the TAI groups, with the last AI at 366 DIM. Pregnant cows were dried off at $220 \mathrm{~d}$ of gestation, and gestation length was set at $280 \mathrm{~d}$; therefore, the dry period was set at $60 \mathrm{~d}$. Pregnancy loss was set at $11.3 \%$, with $9.6 \%$ occurring from 32 to $90 \mathrm{~d}$ of gestation and $1.7 \%$ occurring from $90 \mathrm{~d}$ of gestation to term (based on data from Santos et al., 2004; McClure, 2007; Brick et al., 2012). After an abortion, cows in the ED and TAI-ED groups returned to estrus following a $\log$ normal distribution with mean (SD) of $19 \mathrm{~d}$ (11 d), based on data from Parmigiani et al. (1978) and Kastelic and Ginther (1989). Cows in the TAI group were re-enrolled in the Ovsynch after nonpregnancy diagnosis at 91 or $200 \mathrm{~d}$ after AI. Stillbirth probability was set at $6.5 \%$ according to previous reports (Bicalho et al., 2008; Schuenemann et al., 2011).

\section{Milk and Fat Production}

Daily milk yield (MY) was calculated using Wood's (1967) incomplete gamma function with adjustments for pregnancy as previously reported (De Vries, 2001; De Vries et al., 2006). Mathematically,

$$
\begin{aligned}
\operatorname{MY}(\mathrm{kg} / \mathrm{d}) & =\mathrm{a} \times \mathrm{DIM}^{\mathrm{b}} \times \exp (-\mathrm{c} \times \mathrm{DIM}) \\
\times & {\left[1+(\mathrm{DPREG} / \mathrm{d})^{2}\right]^{-1} }
\end{aligned}
$$

where DPREG is the number of days pregnant, and a, $\mathrm{d}$, c, and d are parameters of the function. Parameters a through d for first parity were 16.27, 0.19, 0.001425, and 509.3; for second parity, 23.81, 0.1652, 0.002208, and 393.2; and for third and greater parities, 21.83, $0.2210,0.003002$, and 355.7 , respectively.

Daily fat percentage in milk (fat \%) and FCM were modeled, for all lactations, as previously described (De Vries, 2001, De Vries et al., 2006). Mathematically,

$$
\begin{aligned}
& \text { Fat } \%=12.86 \times \mathrm{DIM}^{-1.081} \times \exp [0.0926 \\
&\left.\times(\operatorname{lnDIM})^{2}\right] \times(\operatorname{lnDIM})^{1.107} \\
& \text { FCM }(\mathrm{kg} / \mathrm{d})=0.4 \times \mathrm{MY}+0.15 \times \text { Fat } \% \times \mathrm{MY}
\end{aligned}
$$

\section{$B W$}

Body weight was modeled as previously described (van Arendonk, 1985; De Vries, 2001; De Vries et al., 2006).

$$
\begin{gathered}
\mathrm{BW}(\mathrm{kg})=\mathrm{A} \times\left\{1-\left[1-(\mathrm{B} / \mathrm{A})^{1 / 3}\right]\right. \\
\times \exp (-\mathrm{C} \times \mathrm{AGE})\}^{3}-(\mathrm{P} 1 / \mathrm{P} 2) \times \mathrm{DIM} \\
\times \exp (1-\mathrm{DIM} / \mathrm{P} 2)+\mathrm{P} 3^{3} \times \mathrm{DPC}^{3}
\end{gathered}
$$

where AGE is the cow's age in days, and DPC is 0 to $50 \mathrm{~d}$ of gestation (calculated by subtracting 50 from the gestation days). The parameters mature liveweight (kg; A), birth weight (kg; B), growth rate parameter (C), maximum decrease of liveweight during lactation (P1), time during the lactation with minimum liveweight (P2), and pregnancy parameter (P3) for first parity were $600,42,0.0039,20,65$, and 0.0187 , and for second 
and greater parities were $600,42,0.0060,40,75$, and 0.0187 .

\section{DMI}

Dry matter intake $(\mathrm{kg} / \mathrm{d})$ for lactating cows was calculated as recommended by the NRC (2001), as previously reported (De Vries et al., 2006):

$$
\begin{gathered}
\mathrm{DMI}=0.372 \times \mathrm{FCM}+0.0968 \times \mathrm{BW}^{0.75} \\
\times\{1-\exp [-0.192 \times(\mathrm{DIM} / 7+3.67)]\} .
\end{gathered}
$$

Dry cows were assumed to consume $12 \mathrm{~kg}$ of DM/d, as previously reported (De Vries et al., 2006).

\section{Culling and Replacements}

Cows were culled if the income from milk sales was lower than the cost of production (feeding cost + other costs) or if they were not pregnant by 450 DIM. Furthermore, a probability of involuntary culling was set at $0.1 \% / \mathrm{d}$ for the first $60 \mathrm{DIM}$, and $0.03 \% / \mathrm{d}$ for the remaining of the lactation and dry period (based on data from Dechow and Goodling, 2008; Pinedo and De Vries, 2010). The probability of death was set at $0.05 \% / \mathrm{d}$ for the first $60 \mathrm{DIM}$, and $0.0076 \% / \mathrm{d}$ for the remaining of the lactation and dry period (based on data from Dechow and Goodling, 2008; Pinedo and De Vries, 2010). For each cow that was culled or died, a pregnant heifer (730 d old; $280 \mathrm{~d}$ pregnant) was immediately purchased as replacement. Therefore, herd size remained constant.

\section{Costs and Incomes}

Estrus detection cost in all lactating cows was set at $\$ 0.15 /$ cow per day, assuming an employee makes $\$ 15 / \mathrm{h}$ and can observe 100 cows for signs of estrus in $1 \mathrm{~h}$. Price of $\mathrm{GnRH}$ was set at $\$ 2.40 /$ dose, and that of $\mathrm{PGF}_{2 \alpha}$ was set at $\$ 2.65 /$ dose (average commercial prices in July 2012). The price range for GnRH was $\$ 2.00$ to $\$ 2.80$ and for $\mathrm{PGF}_{2 \alpha}$ was $\$ 2.30$ to $\$ 3.00$. Injection cost was set at $\$ 0.25 /$ injection, assuming an employee makes $\$ 15.00 / \mathrm{h}$ and can give 60 injections per hour. Semen cost was set at $\$ 10.00 /$ straw. Cost of AI was set at $\$ 5.00 /$ AI. Pregnancy diagnosis cost was set at $\$ 3.00 /$ diagnosis. Calf price (average for male and female) was set at $\$ 140 /$ calf. Milk price was modeled at $\$ 0.33$ and $\$ 0.44 / \mathrm{kg}$. Dry matter price was set at $\$ 0.25 / \mathrm{kg}$ for lactating cows and at $\$ 0.15 / \mathrm{kg}$ for dry cows. Cull price was modeled at $\$ 0.65 / \mathrm{kg}$ of live weight with milk price at $\$ 0.33$ and $\$ 0.44 / \mathrm{kg}$ or at $\$ 1.65 / \mathrm{kg}$ of live weight with milk price at $\$ 0.44 / \mathrm{kg}$ to evaluate conditions of low milk price and low cull price, high milk price and low cull price, and high milk price and high cull price. Replacement heifer price was set at $\$ 1,600.00 /$ heifer. Other variable and fixed costs were set at $\$ 2.50 /$ cow per day.

\section{Experimental Design}

Four factors that could affect the economic benefits of the 3 different reproductive programs were compared: estrus detection (40 vs. 60\%), accuracy of estrus detection (85 vs. 95\%), compliance with each injection of the synchronization protocol (85 vs. 95\%), and milk price $(\$ 0.33$ vs. $\$ 0.44 / \mathrm{kg})$. Values for estrus detection followed previous reports (De Vries et al., 2006). Values for accuracy of estrus detection were extracted from a review by Heersche and Nebel (1994). The values for compliance with each injection of the synchronization protocol matched the values for accuracy of estrus detection. Milk price was modeled to represent $\$ 15$ or $\$ 20$ per 100 lbs. This design would generate 28 scenarios: 8 scenarios for ED [40 (ED40) or 60\% (ED60) estrus detection, 85 or $95 \%$ accuracy of estrus detection (ED40-85 or ED40-95), and $\$ 0.33$ or $0.44 / \mathrm{kg}$ of milk], 4 scenarios for TAI [ 85 or $95 \%$ compliance (TAI85 or TAI-95) with injections, and $\$ 0.33$ or $0.44 / \mathrm{kg}$ of milk], and 16 scenarios for TAI-ED (40 or $60 \%$ estrus detection, 85 or $95 \%$ accuracy of estrus detection, 85 or $95 \%$ compliance with injections, and $\$ 0.33$ or 0.44 / $\mathrm{kg}$ of milk). However, for TAI-ED only, the extremes for accuracy of estrus detection and compliance with injections were compared (85\% for both vs. $95 \%$ for both; TAI-ED40-85, TAI-ED40-95, TAI-ED60-85, and TAI-ED60-95). Therefore, 20 different scenarios were evaluated. For the ED40-85 and ED40-95 models, 34 and $38 \%$ of the AI were accurate, respectively. For the E60-85 and ED60-95 models, 57 and $51 \%$ of the AI were accurate, respectively.

For each reproductive program, all the combinations of probability of estrus detection, accuracy of estrus detection, and compliance with each injection were run separately for $\$ 0.33 / \mathrm{kg}$ of milk and then for $0.44 / \mathrm{kg}$ of milk. For each set of parameters, 100 simulations for a herd of 1,000 cows were run for 5,000 d. In the beginning of the simulation, each herd was composed of $33.3 \%$ of the cows each in the first, second, and third lactations. Age of first-lactation cows was set at $730 \mathrm{~d}$, second lactation at 1,155 d, and third lactation at 1,580 $\mathrm{d}$, assuming a calving interval of $425 \mathrm{~d}$. Simulation started with cows in their first day of lactation. Usually it took between 1,500 and 2,000 d for each herd to reach steady state (determined by visual observation; Figure 1); therefore, the first 3,000 d were excluded 
Table 1. Calculation of service rate (SR), conception rate $(\mathrm{CR})$, and pregnancy rate (PR) for the timed AI model with $95 \%$ compliance with each injection

\begin{tabular}{|c|c|c|c|c|c|c|}
\hline Cycle & $\begin{array}{c}\text { Eligible, } \\
\text { no. }\end{array}$ & $\begin{array}{l}\text { AI, } \\
\text { no. }\end{array}$ & $\begin{array}{l}\mathrm{SR}, \\
\%\end{array}$ & $\begin{array}{c}\text { Pregnant, } \\
\text { no. }\end{array}$ & $\begin{array}{c}\mathrm{CR}, \\
\%\end{array}$ & $\begin{array}{c}\mathrm{PR}, \\
\%\end{array}$ \\
\hline 1 & 1,000 & 1,000 & 100 & 329 & 32.9 & 32.9 \\
\hline 2 & 671 & 0 & 0 & 0 & - & - \\
\hline 3 & 671 & 671 & 100 & 169 & 25.2 & 25.2 \\
\hline 4 & 502 & 0 & 0 & 0 & - & - \\
\hline 5 & 502 & 502 & 100 & 122 & 24.3 & 24.3 \\
\hline 6 & 380 & 0 & 0 & 0 & - & - \\
\hline 7 & 380 & 380 & 100 & 91 & 23.9 & 23.9 \\
\hline 8 & 289 & 0 & 0 & 0 & - & - \\
\hline 9 & 289 & 289 & 100 & 67 & 23.2 & 23.2 \\
\hline 10 & 222 & 0 & 0 & 0 & - & - \\
\hline 11 & 222 & 222 & 100 & 49 & 22.1 & 22.1 \\
\hline 12 & 173 & 0 & 0 & 0 & - & - \\
\hline 13 & 173 & 173 & 100 & 38 & 22.0 & 22.0 \\
\hline 14 & 135 & 0 & 0 & 0 & - & - \\
\hline 15 & 135 & 135 & 100 & 28 & 20.7 & 20.7 \\
\hline Total & 5,744 & 3,372 & 58.7 & 893 & 26.5 & 15.5 \\
\hline
\end{tabular}

from the technical and economic analysis. Steady state is reached when the mean and variance do not change when shifted in time or space. Net daily value was calculated by subtracting the costs of replacement heifers, feeding costs, breeding costs, and other costs from the daily income from milk sales, cow sales, and calf sales. The net daily value was averaged for the last 2,000 d of simulation and profit/cow per year was calculated. To evaluate reproductive parameters such as SR, CR, PR, median days open (MDO), and proportion of pregnant cows at 366 DIM (PP366), the models were run 100 times for $366 \mathrm{~d}$ without culling, deaths, abortion, or calving. The number of eligible cows, number or cows $\mathrm{AI}$, and number of cows that conceived were calculated for every $21 \mathrm{~d}$ cycle after the end of the VWP (50 DIM for ED, and 72 DIM for TAI and TAI-ED). The total number of cows eligible, AI, and pregnant were used to calculate SR, CR, and PR at the end of the breeding period (Table 1). Proportion of pregnant cows in each day was averaged for the 100 runs, and the day the pro-

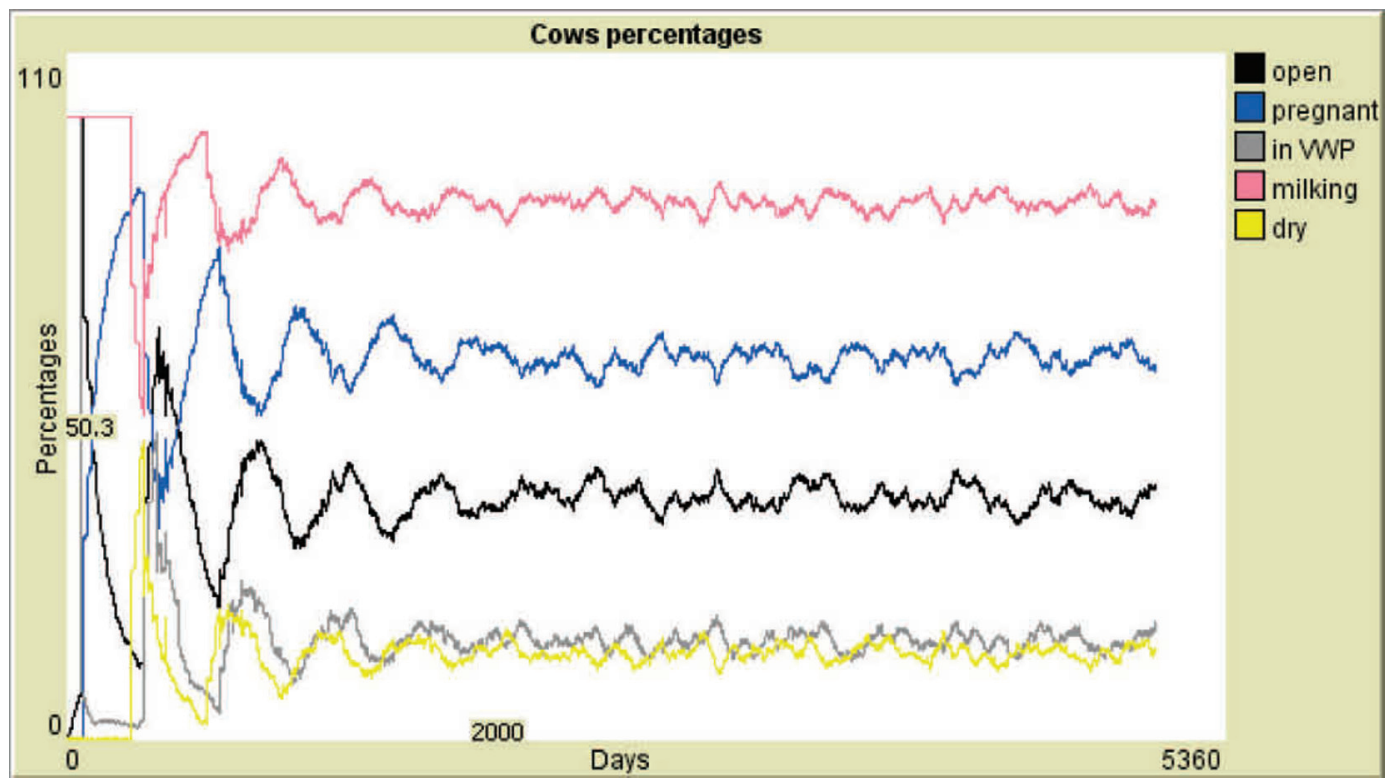

Figure 1. Graphic interface of NetLogo (http://ccl.northwestern.edu/netlogo) using a model that combined timed AI (TAI) and estrus detection (ED) as an example in a 5,000-d run. VWP = voluntary waiting period. From top to bottom: milking, pregnant, open, in VWP, and dry. Color version available in the online PDF. 
portion of pregnant cows reached $50 \%$ was considered as MDO. Proportion of pregnant cows at 366 DIM was averaged for 100 runs.

\section{Statistical Analysis}

Data obtained after 100 runs for each scenario such as daily number of cows pregnant, lactating, culled and died, milk yield, estrus detection cost, synchronization cost, AI cost, diagnostic cost, feeding cost, replacement cost, other cost, milk income, calf sales income, cow sales income, and net income were exported into an Excel spreadsheet (Microsoft Corp., Redmond, WA) for data organization in preparation for statistical analysis. The cumulative yearly profits for each scenario were compared by ANOVA using the GLM procedure of SAS (SAS Institute Inc., Cary, NC). Differences with $P$-value $\leq 0.05$ were considered statistically significant.

\section{RESULTS AND DISCUSSION}

\section{Overview}

Herein, we used a stochastic dynamic dairy herd simulation model to evaluate the technical and economic performance of different reproductive programs that use ED, TAI, or a combination of both. An advantage of the stochastic model compared with a deterministic model is the ability to evaluate variability in the outcomes of interest. Also, this is the first time that important factors for reproductive success such as accuracy of $\mathrm{ED}$ and compliance with the injections for the TAI protocol are evaluated. Using the NetLogo platform to build the model also allowed real-time evaluation of several components of the model, such as proportion of pregnant, nonpregnant, lactating, or dry cows, milk yield, culling, and profit. Figure 1 shows the TAI-ED model after a run for $5,000 \mathrm{~d}$. It can be observed that the model stabilizes after approximately 2,000 d.

\section{Effect of Different Reproductive Programs on Reproductive Parameter Outcomes}

Reproductive parameter outcomes are shown in Table 2. Observed SR was very close to the specified ED rate set for the ED models. Although in the TAI model, cows were AI every other cycle, SR was close to $60 \%$ because of the large effect of the first AI, when all cows were AI, and also to a lesser extent because the breeding period ended with all cows being AI one last time (Table 1). The combination of TAI and ED (TAI-ED) resulted in the highest SR.

Both accuracy of ED and compliance with each injection affected CR; however, compliance with injec-

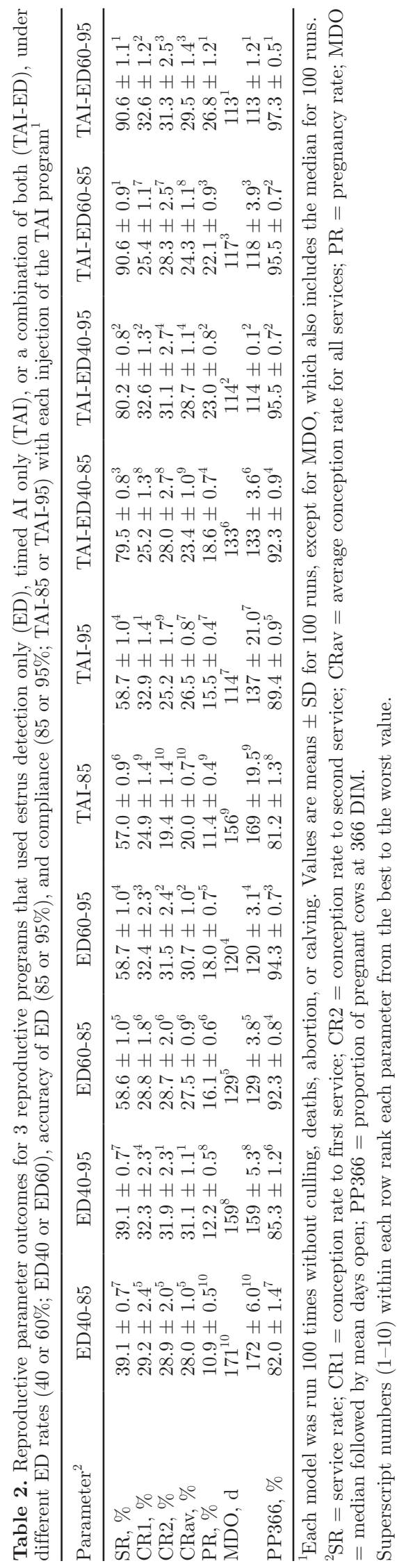

Journal of Dairy Science Vol. 96 No. 4, 2013 
tions had a greater detriment to $\mathrm{CR}$ because of the compounded effect (e.g., $0.85 \times 0.85=0.73$ and 0.85 $\times 0.85 \times 0.85=0.61)$, where the chance of a cow receiving all injections for the presynchronization was only $73 \%$, and the chance of a cow receiving all injections for the Ovsynch was only $61 \%$ for the TAI- 85 model. For the TAI-95 model, the values would be 90 and $85 \%$, respectively. On the other hand, although the CR after inaccurate ED (2.1\%) was lower than the CR after missing an injection of Ovsynch (5.2\%), it affected a lower proportion of cows (2\% for ED40-95 to 9\% for ED60-85). This can be clearly observed in the TAI-ED models with $85 \%$ accuracy and $85 \%$ compliance, where the first service was lower than the second service. The highest mean CR was observed for the ED models with 95\% accuracy and the lowest mean CR for the TAI-85 model. However, the TAI models with $95 \%$ compliance had the highest first-service CR because of the beneficial effect of presynchronization.

Pregnancy rate was low for ED40 models (lowest for the ED40-85 model) and for the TAI-85 model because of low SR and low CR, respectively. Pregnancy rates increased by increasing SR in the ED60 models (highest for the TAI-ED60-95 model) and by increasing CR in the TAI-95 model. Compliance with each injection had a greater effect on PR than accuracy of ED. Although PR increased from $11.8 \%$ (from 16.1 to 18.0 ) to $11.9 \%$ (from 10.9 to 12.2 ) by going from 85 to $95 \%$ accuracy in the ED40 and ED 60 models, PR increased by $36 \%$ by going from 85 to $95 \%$ compliance in the TAI models. Therefore, compliance with injections is crucial for the success of programs that rely solely on TAI.

Median days open was shorter for TAI-85 than for the ED40 models and shorter for TAI-95 than for the ED60 models (Table 2). Nonetheless, mean days open were longer for TAI-85 compared with ED40-95 and for TAI-95 compared with the ED60 models. This is mainly because of the long and fixed re-insemination interval (42 d) leading cows to have either 156 or $198 \mathrm{~d}$ open in the TAI-85 model or 114 or $156 \mathrm{~d}$ open in the TAI-95 model. The survival curves are shown in Figure 2. Although ED40-85 had the lowest PR, PP366 was actually slightly higher than the TAI- 85 model because of the shorter VWP for the ED models, and the long re-insemination interval and the lower CR for the TAI models, especially that with $85 \%$ compliance. Therefore, although the models with TAI achieved a higher proportion of pregnant cows after the first service, all the ED models achieve a higher proportion of pregnant cows by the end of the breeding period than the TAI- 85 model. Furthermore, the ED60-85 and ED60-95 models achieved a higher proportion of pregnant cows by the end of the breeding period than the TAI-95 model. In summary, combining TAI and ED increased PR, decreased MDO, and increased PP366.

\section{Effect of Different Reproductive Programs on Technical and Economic Results}

Technical and economic results for the 3 reproductive programs with milk price set at $\$ 0.33 / \mathrm{kg}$ and $\$ 0.44 / \mathrm{kg}$ are shown in Table 3 . First, the technical and economic results for the models with milk at $\$ 0.33 / \mathrm{kg}$ are in line with previous reports (De Vries, 2006; De Vries et al., 2006). Nonetheless, others have reported much higher profits per cow per year (Giordano et al., 2011). This is
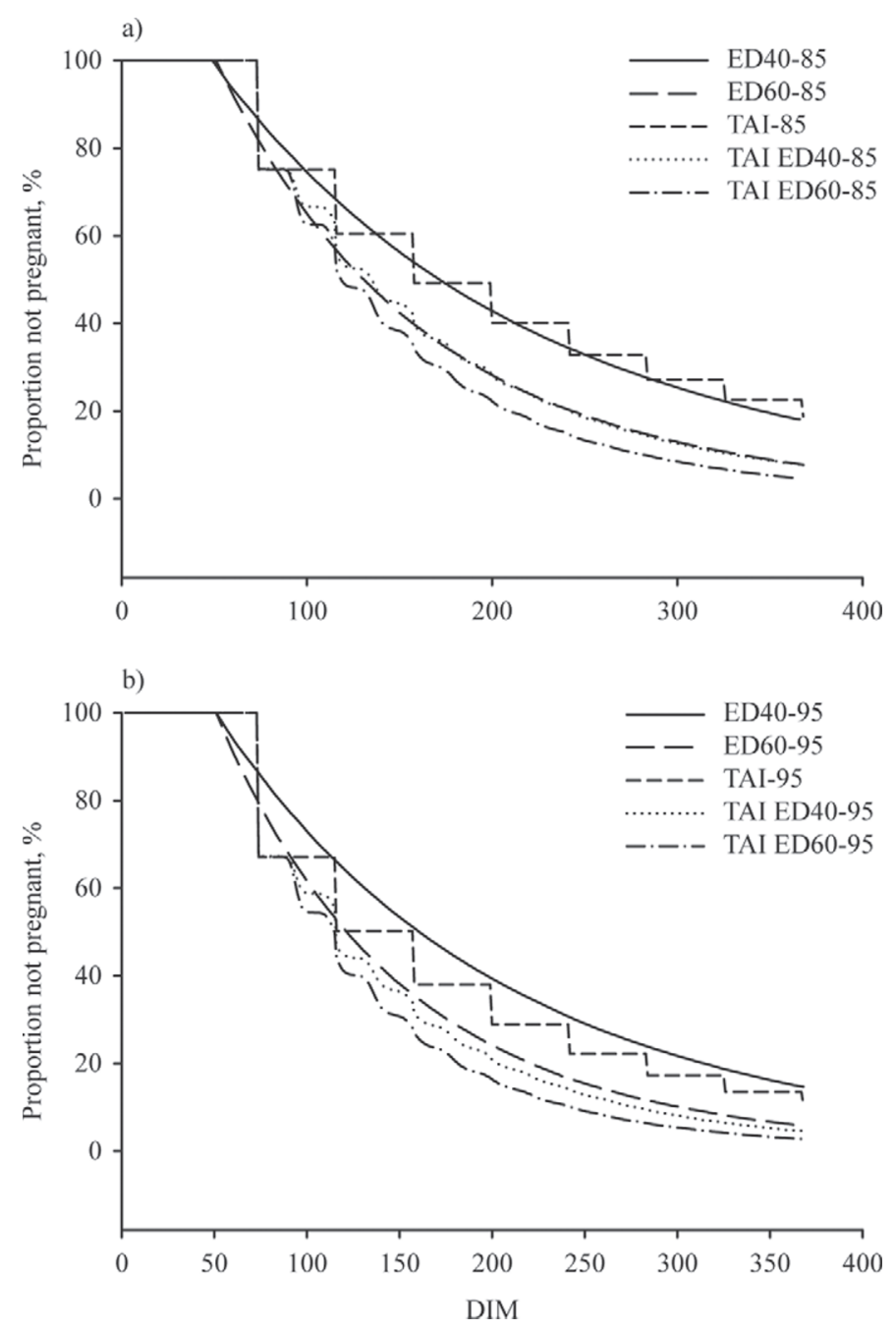

Figure 2. Proportion of nonpregnant cows for 3 reproductive programs that used estrus detection only (ED), timed AI only (TAI), or a combination of both (TAI-ED), under different ED rates (40 or $60 \%$ ), accuracies of ED: (panel a) 85\% and (panel b) 95\%, and compliance: (panel a) $85 \%$ and (panel b) $95 \%$, with each injection of the TAI program. 
partly because in the model by Giordano et al. (2011) fixed and other variable costs were not accounted for, thereby decreasing the cost of production by $\$ 912.5 /$ yr. Furthermore, milk price and cull price were slightly higher. The ED40 models resulted in greater profits than the TAI-85 model but lower than the TAI-95 model. Both ED60 models resulted in greater profits than the TAI-95 model. In herds that use only ED, adding TAI would increase overall profit/cow per year by $\$ 46.8$ (TAI-ED40-85 vs. ED40-85) to $\$ 68.8$ (TAIED40-95 vs. ED40-95), and by $\$ 8.9$ (TAI-ED60-85 vs. ED60-85) to $\$ 26.9$ (TAI-ED60-95 vs. ED60-95). Our findings corroborate with the observations by Giordano et al. (2011), where profits were increased if TAI was combined with ED at any level of ED (from 10 to $80 \%$ ED). Adding ED to a TAI program is effective because it increases SR and decreases the interbreeding inter- val. As expected, the benefit from adding TAI to an ED program was highest when ED was lowest (Tenhagen et al., 2004). In herds that use only TAI, adding ED would increase profit by $\$ 64.2$ (TAI-ED40-85 vs. TAI$85)$ to $\$ 96.3$ (TAI-ED60-85 vs. TAI- 85 ), and by $\$ 31.8$ (TAI-ED40-95 vs. TAI-95) to $\$ 59.7$ (TAI-ED60-95 vs. TAI-95). Adding ED to a TAI program has the greatest effect when compliance is poor (85\%), even with low SR $(40 \%)$ and poor accuracy (85\%). This is because CR is higher for ED with poor accuracy than for TAI with poor compliance.

Although compliance is critical for the success of TAI and TAI-ED programs, it is often overlooked. One might think of compliance simply as missing injections for cows on a list, and as such, $85 \%$ compliance might seem very low. Nonetheless, compliance starts with manufacturing the correct list. The authors have

Table 3. Steady-state technical and economic ( $\$ /$ cow per year) results for 3 reproductive programs that used estrus detection only (ED), timed artificial insemination only (TAI) or a combination of both (TAI-ED), under different ED rate (40 or $60 \%$; ED40 or ED60), accuracy of ED (85 or $95 \%$ ), and compliance (85 or $95 \%$; TAI-85 or TAI-95) with each injection of the TAI program with milk price set at $\$ 0.33 / \mathrm{kg}$ (top row for each parameter), followed by results when milk price was set at $\$ 0.44 / \mathrm{kg}$ (bottom row of each parameter)

\begin{tabular}{|c|c|c|c|c|c|c|c|c|c|c|}
\hline Item & ED40-85 & ED40-95 & ED60-85 & ED60-95 & TAI-85 & TAI-95 & $\begin{array}{c}\text { TAI- } \\
\text { ED40-85 }\end{array}$ & $\begin{array}{c}\text { TAI- } \\
\text { ED40-95 }\end{array}$ & $\begin{array}{c}\text { TAI- } \\
\text { ED60-85 }\end{array}$ & $\begin{array}{c}\text { TAI- } \\
\text { ED60-95 }\end{array}$ \\
\hline \multirow[t]{2}{*}{ Pregnant, $\%^{\mathrm{a}, \mathrm{A}}$} & 45.6 & 47.8 & 53.3 & 55.2 & 46.0 & 52.4 & 54.5 & 58.3 & 57.2 & 60.4 \\
\hline & 45.8 & 48.0 & 53.6 & 55.5 & 46.2 & 52.7 & 54.8 & 58.9 & 57.6 & 60.8 \\
\hline \multirow[t]{2}{*}{ Lactating, $\%$ b,B } & 84.8 & 84.1 & 82.9 & 82.6 & 83.8 & 82.0 & 81.9 & 81.1 & 81.3 & 80.9 \\
\hline & 89.2 & 88.6 & 87.4 & 86.9 & 88.6 & 87.0 & 87.0 & 86.1 & 86.3 & 85.6 \\
\hline \multirow[t]{2}{*}{ Culling, $\%^{\mathrm{c}, \mathrm{C}}$} & 40.3 & 38.3 & 34.2 & 33.0 & 38.6 & 32.8 & 31.4 & 28.8 & 29.4 & 27.5 \\
\hline & 40.5 & 38.7 & 34.5 & 33.4 & 38.9 & 33.1 & 31.7 & 28.9 & 29.6 & 27.8 \\
\hline \multirow[t]{2}{*}{ Milk, $\mathrm{kg} / \mathrm{d}^{\mathrm{d}, \mathrm{D}}$} & 33.8 & 34.0 & 34.4 & 34.5 & 33.8 & 34.4 & 34.5 & 34.8 & 34.7 & 35.0 \\
\hline & 33.2 & 33.3 & 33.7 & 33.9 & 33.2 & 33.6 & 33.8 & 34.1 & 34.0 & 34.2 \\
\hline \multirow[t]{2}{*}{ Milk sales $^{\mathrm{e}, \mathrm{E}}$} & $3,450.5$ & $3,441.0$ & $3,431.0$ & $3,433.3$ & $3,414.9$ & $3,391.2$ & $3,404.9$ & $3,400.0$ & $3,402.3$ & $3,405.2$ \\
\hline & $4,750.9$ & $4,743.9$ & $4,730.0$ & $4,724.5$ & $4,718.5$ & $4,693.9$ & $4,719.2$ & $4,712.3$ & $4,713.6$ & $4,705.5$ \\
\hline \multirow[t]{2}{*}{ Cows sales $^{\mathrm{f}, \mathrm{F}}$} & 132.3 & 124.5 & 108.7 & 104.2 & 126.0 & 103.7 & 97.8 & 87.6 & 90.0 & 82.6 \\
\hline & 133.1 & 126.0 & 109.7 & 105.1 & 127.2 & 104.4 & 99.0 & 88.2 & 90.8 & 83.7 \\
\hline \multirow[t]{2}{*}{ Calf sales ${ }^{\mathrm{g}, \mathrm{G}}$} & 122.4 & 123.4 & 126.2 & 127.7 & 120.9 & 123.2 & 124.4 & 126.9 & 125.9 & 128.4 \\
\hline & 123.1 & 124.0 & 127.2 & 128.6 & 121.7 & 124.0 & 125.3 & 128.0 & 126.8 & 129.4 \\
\hline \multirow[t]{2}{*}{ Replace costs ${ }^{\mathrm{h}, \mathrm{H}}$} & 645.2 & 613.3 & 547.5 & 528.4 & 618.0 & 525.3 & 502.1 & 460.6 & 470.2 & 439.2 \\
\hline & 647.5 & 619.3 & 552.6 & 534.0 & 622.7 & 529.0 & 506.5 & 462.4 & 473.4 & 444.5 \\
\hline \multirow[t]{2}{*}{ Breeding costs ${ }^{\mathrm{i}, \mathrm{I}}$} & 91.1 & 88.7 & 97.2 & 94.1 & 104.1 & 91.6 & 136.1 & 126.5 & 131.9 & 123.0 \\
\hline & 93.8 & 91.5 & 100.0 & 96.6 & 104.8 & 92.0 & 139.8 & 130.0 & 135.5 & 126.3 \\
\hline \multirow[t]{2}{*}{ Feeding $\operatorname{costs} \mathrm{s}^{\mathrm{j}, \mathrm{J}}$} & $1,801.9$ & $1,795.5$ & $1,784.2$ & $1,782.0$ & $1,790.0$ & $1,773.1$ & $1,774.9$ & $1,767.6$ & $1,770.1$ & $1,766.3$ \\
\hline & $1,851.0$ & $1,846.2$ & $1,834.3$ & $1,829.6$ & $1,843.9$ & $1,829.4$ & $1,832.8$ & $1,824.5$ & $1,827.1$ & $1,819.3$ \\
\hline Other $\operatorname{costs}^{\mathrm{k}, \mathrm{K}}$ & 912.5 & 912.5 & 912.5 & 912.5 & 912.5 & 912.5 & 912.5 & 912.5 & 912.5 & 912.5 \\
\hline \multirow{2}{*}{ Profit ${ }^{1, L}$} & $254.6^{9}$ & $278.8^{8}$ & $324.6^{5}$ & $348.3^{2}$ & $237.2^{10}$ & $315.5^{6}$ & $301.4^{7}$ & $347.3^{3}$ & $333.5^{4}$ & $375.2^{1}$ \\
\hline & $1,502.2^{9}$ & $1,524.4^{8}$ & $1,567.9^{5}$ & $1,585.5^{3}$ & $1,483.4^{10}$ & $1,559.5^{6}$ & $1,552.0^{7}$ & $1,599 \cdot 1^{2}$ & $1,582.8^{4}$ & $1,616.0^{1}$ \\
\hline
\end{tabular}

${ }^{\mathrm{a}-\mathrm{l}}$ Lowercase superscripts indicate differences when milk price was set at $\$ 0.33 / \mathrm{kg} ;{ }^{\mathrm{a}}$ all values differ $(P<0.001 ;$ SE $=0.04) ;{ }^{\mathrm{b}}$ all values differ $(P$ $<0.001 ; \mathrm{SE}=0.04)$, except TAI-95 vs. TAI-ED40-85 $(P=0.12)$; ${ }^{\mathrm{c}}$ all values differ $(P<0.01 ; \mathrm{SE}=0.08)$, except ED60-95 vs. TAI-95 $(P=0.08)$ dall values differ $(P<0.001 ; \mathrm{SE}=0.005)$, except ED60-85 vs. TAI-95 $(P=0.43)$; ${ }^{\mathrm{e}}$ all values differ $(P<0.05 ;$ SE $=1.62)$, except TAI-ED40-85 vs. TAI-ED60-85 and TAI-ED60-95 $(P>0.25)$, TAI-ED40-95 vs. TAI-ED60-85 $(P=0.31)$, and TAI-ED60-85 vs. TAI-ED60-95 $(P>0.21) ;{ }^{\mathrm{f}}$ all values differ $(P<0.001 ; \mathrm{SE}=0.25)$, except ED60-95 vs. TAI-95 $(P=0.15)$; ${ }^{\mathrm{g}}$ all values differ $(P<0.02 ; \mathrm{SE}=0.10)$, except ED40-95 vs. TAI-95 $(P=0.23) ;{ }^{h}$ all values differ $(P<0.01 ; \mathrm{SE}=1.2)$, except ED60-95 vs. TAI-95 $(P=0.08) ;{ }^{\mathrm{i}}$ all values differ $(P<0.001 ;$ SE $=0.07) ;{ }^{j}$ all values differ $(P<0.03$; SE $=0.51)$, except TAI-ED40-95 vs. TAI-ED60-95 $(P=0.09) ;{ }^{k}$ all values are equal (fixed cost); ${ }^{1}$ all values differ $(P<0.001$; $\mathrm{SE}=1.26)$, except ED60-95 vs. TAI-ED40-95 $(P=0.59)$

${ }^{\mathrm{A}-\mathrm{L}}$ Uppercase superscripts indicate differences when milk price was set at $\$ 0.44 / \mathrm{kg}$; ${ }^{\mathrm{A}}$ all values differ $(P<0.001 ;$ SE $=0.04)$; ${ }^{\mathrm{B}}$ all values differ $(P<0.05 ; \mathrm{SE}=0.03)$, except ED40-95 vs. TAI-85 $(P=0.10)$, ED60-95 vs. TAI-95 $(P=0.18)$, and TAI-95 vs. TAI-ED40-85 $(P=0.51) ;{ }^{\mathrm{C}}$ all values differ $(P<0.05 ; \mathrm{SE}=0.07)$; ${ }^{\mathrm{D}}$ all values differ $(P<0.001 ; \mathrm{SE}=0.004)$, except ED40-85 vs. TAI-85 $(P=0.30)$; ${ }^{\mathrm{E}}$ all values differ $(P \leq$ $0.05 ; \mathrm{SE}=1.76)$, except TAI-85 vs. TAI-ED40-85 $(P=0.77)$, and TAI-ED40-96 vs. TAI-ED60-85 $(P=0.59) ;{ }^{\mathrm{F}}$ all values differ $(P<0.001 ;$ SE $=0.25)$, except ED60-95 vs. TAI-95 $(P=0.06) ;{ }^{\mathrm{G}}$ all values differ $(P<0.001 ; \mathrm{SE}=0.09)$, except ED40-95 vs. TAI-95 $(P=0.97)$; ${ }^{\mathrm{H}}$ all values differ $(P<0.04 ; \mathrm{SE}=1.2) ;{ }^{\mathrm{I}}$ all values $\operatorname{differ}(P<0.001 ; \mathrm{SE}=0.07)$; ${ }^{\mathrm{J}}$ all values differ $(P<0.02 ; \mathrm{SE}=0.43)$, except ED60-95 vs. TAI-95 $(P=$ $0.77) ;{ }^{\mathrm{K}}$ all values are equal (fixed cost); ${ }^{\mathrm{L}}$ all values differ $(P<0.001 ; \mathrm{SE}=1.50)$, except ED60-95 vs. TAI-ED60-85 $(P=0.21)$. 
troubleshot reproductive problems in herds and discovered that only 70 to $75 \%$ of the cows were AI for the first service in a $100 \%$ TAI program because of missing cows when generating the AI list. Even in herds with good compliance, only approximately 95 to $97 \%$ of the cows are AI upon completion of a TAI protocol, either because cows are missed or because the AI technician decided not to AI the cow (e.g., cows with purulent discharge, cow with certain diseases such as mastitis, cows in which the cervix cannot be passed, cows with uterine adhesions). Other issues with list manufacturing include entering incorrect information for AI or pregnancy diagnoses that lead to nonpregnant cows not being re-enrolled in the program, cows that were AI not coming up for pregnancy diagnosis, or pregnant cows receiving prostaglandin. Even if the list is correct, usually not all the cows are found for hormone administration, especially in large herds; therefore, the diligence of the person responsible for hormone administration dictates how high or low compliance is. Often, mistakes also occur when ear tags are misread. Given these issues, herd managers who are risk averse might favor ED or even natural breeding over TAI (Overton, 2005; Lima et al., 2010).

The technical results for the models with milk at $\$ 0.44 / \mathrm{kg}$ are in line with previous reports (De Vries, 2006; De Vries et al., 2006); however, the profits were higher than in previous reports (De Vries, 2006; De Vries et al., 2006), because of higher milk prices, but were still lower than other reports (Giordano et al., 2011). In general, with higher milk prices, the proportion of lactating cows increased because there was no culling due to milk sales being lower than the cost of production; therefore, all cows that did not get pregnant remained in the herd until 450 DIM. As a consequence, milk yield was decreased. Economic results were similar to the models with milk price at $\$ 0.33 / \mathrm{kg}$, with the only change being that TAI-ED40-95 was slightly more profitable than ED60-95. Of greater importance is the fact that the percentage increase in profit when ED or TAI was added to a program that used only one was much greater when milk price was lower. When milk price was $\$ 0.33 / \mathrm{kg}$, the difference in profits for TAIED40-85 versus ED40-85 (\$46.8) and for TAI-ED40-95 versus ED40-95 (\$68.8) represented an increase in profit of 18.4 to $24.7 \%$. When milk price was $\$ 0.44$ / $\mathrm{kg}$, the difference in profits for TAI-ED40-85 versus ED40-85 (\$49.8) and for TAI-ED40-95 versus ED40-95 $(\$ 74.7)$ would represent an increase in profit of only 3.2 to $4.9 \%$. The increase in profit would be even less significant if SR was good. The difference in profits for TAI-ED60-85 versus ED60-85 (\$14.9) and for TAIED60-95 versus ED60-95 (\$30.5) represents an increase of only 0.9 to $1.9 \%$. The difference in profits for TAIED60-85 versus ED60-85 (\$14.9) and for TAI-ED60-95 versus ED60-95 (\$30.5) represents an increase of only 0.9 to $1.9 \%$. Therefore, reproductive performance is not as critical when milk prices are high as when milk prices are low. However, dairies should still strive for good reproductive performance because it cannot be improved as fast as milk prices can decrease.

\section{Choosing the Most Profitable Program}

Although adding ED or TAI to a program that uses either one only would increase profits, it was not always the program that showed the best reproductive parameters, such as PR, MDO, and PP366, and proportion of pregnant cows in the herd, that had the highest profits. In general, as the proportion of pregnant cows in the herd increased, milk yield increased, culling rate decreased, and proportion of lactating cows decreased. Although there is a benefit to improving reproductive performance by increasing milk yield and decreasing culling, it may be offset by a decreased proportion of lactating cows in the herd. Furthermore, although breeding costs decrease with increased reproductive performance for each program (ED, TAI, or TAIED), costs were higher for programs that used TAI or a combination of TAI and ED. Therefore, although $\mathrm{PR}$ and proportion of pregnant cows were higher for TAI-85 than for ED40-85, and higher for TAI-95 than for ED40-95, profits were lower. Likewise, although $\mathrm{PR}$ and proportion of pregnant cows in the herd were higher for TAI-ED40-85 than for ED60-85, for ED6095, and for TAI-95, profits were lower. Similarly, profits were lower for TAI-ED60-85 than for ED60-95. These findings corroborate the observations by Tenhagen et al. (2004). They observed that although adding TAI to 2 herds that used ED improved reproductive performance (reduced interval to first AI, increased SR, reduced days open, reduced culling for infertility), it was only economically advantageous in the herd with $29 \%$ SR and not in the herd with $56 \%$ SR.

Regarding the comparison between TAI and ED, our results differed slightly from a previous report (Giordano et al., 2011), using data generated from one study in Wisconsin (Giordano et al., 2012b), where greater profits results for $100 \%$ TAI with resynchronization 32 d after AI than for $100 \%$ ED with $50 \%$ SR. After performing a sensitivity analysis, those researchers concluded that SR had to increase from 50 to $62 \%$ for the ED model to be more profitable than the TAI model. Herein, even the ED60-85 model, which had an overall SR of $58.6 \%$ (49.8\% accurate and $8.8 \%$ inaccurate), had higher profits than TAI-95. The discrepancy 
might have arisen from the assumptions for each model. Herein, we collected data from several published reports and calculated the weighted average of the effect of inaccurate AI, compliance, presynchronization, and Ovsynch itself on CR. In the model by Giordano et al. (2011), the first and subsequent services CR for the 100\% TAI model were 45 and 30\%, respectively, whereas for ED they were 33 and $30 \%$, respectively. Based on data from Moreira et al. (2001), El-Zarkouny et al. (2004), and Navanukraw et al. (2004), we assumed that conception probability following a complete PresynchOvsynch protocol was 29.8\% higher than Ovsynch alone $(29.0 \% \times 1.298=37.6 \%)$, but conception probability for Ovsynch was assumed to be $85.6 \%$ of the conception probability for AI upon accurate estrus detection $(33.9 \% \times 0.856=29.0 \%)$, based on data from Burke et al. (1996), Pursley et al. (1997a,b), and Tenhagen et al. (2004). After accounting for compliance, the CR for first service for the TAI-95 model was $32.9 \%$, decreased to $25.2 \%$, and then continued to decrease $2.6 \%$ for every subsequent service, whereas the first-service CR for the ED60 models ranged from 28.8 (ED60-85) to $32.4 \%$ (ED60-95) and then decreased $2.6 \%$ for every subsequent service.

A recent study using 55,372 AI from 23,695 lactations from 14,148 Holstein cows in 7 herds in New York State reported that CR for first service was $29 \%$, decreasing to 26,25 , and $24 \%$ for second, third, and fourth subsequent services (Hertl et al., 2010). Although the authors stated that all cows in these 7 herds were enrolled in ovulation synchronization and planned breeding programs, they did not compare CR between AI performed after TAI or ED. A report from all the regions in the United States (Norman et al., 2009) showed that CR averaged $31 \%$ in 2006, with the lowest CR in the Southeast $(26 \%)$ and the highest in the Northeast (33\%) and Southwest (33\%). If CR for TAI were increased to $45 \%$ for the first service with $100 \%$ compliance, profit would indeed be higher for TAI than for ED with $50 \%$ SR, $100 \%$ accuracy, and $33 \% \mathrm{CR}$, at either $\$ 0.33 / \mathrm{kg}$ ( $\$ 423.3$ vs. $\$ 324.8)$ or $\$ 0.44 / \mathrm{kg}(\$ 1,661.1$ vs. $\$ 1,564.5)$ milk price. Interestingly, with $50 \%$ SR, $100 \%$ accuracy, and $33 \% \mathrm{CR}$, profits were higher than those of TAI-95 at $\$ 0.33 / \mathrm{kg}$ ( $\$ 324.8$ vs. $\$ 315.5)$ or $\$ 0.44 / \mathrm{kg}(\$ 1,564.5$ vs. $\$ 1,559.5)$ milk price. Even with $50 \%$ SR, $95 \%$ accuracy, and CR for accurate ED of $33.9 \%$, ED was more profitable than TAI-95 at $\$ 0.33 / \mathrm{kg}(317.9$ vs. $\$ 315.5)$ or $\$ 0.44 / \mathrm{kg}(\$ 1,561.7$ vs. $\$ 1,559.5)$ milk price. Therefore, if a given herd is achieving much higher CR using TAI than with ED, it should probably favor TAI; however, if CR for TAI are similar to those of ED, and SR is at least $50 \%$, ED would be more profitable. Therefore, dairy farmers can make an informed decision based on the $\mathrm{CR}$ being achieved on their dairies.

\section{Possible Model Limitation}

One particular aspect of the model is that the total number of cows (lactating plus dry) in the herd is maintained constant instead of the number of lactating cows. Some dairy farmers might try to keep the number of lactating cows constant to reduce idle capacity; however, variation in cow numbers does occur throughout the year, and farmers often cannot or do not try to adjust their lactating cow numbers. Herein, the model with the best reproductive performance (TAI-ED60-95) had 36 to 39 fewer lactating cows than the model with the worst performance (ED40-85). Having fewer lactating cows counteracted the positive effect that improved reproductive performance had on milk yield per lactating cow, so that milk income was actually lower for TAI-ED60-95 than for ED40-85. Ultimately, most of the benefit from improved reproductive performance was because of lower replacement costs. If the number of lactating cows were held constant, herds with better reproduction would have to make investments to house and feed more dry cows, and to purchase more lactating cows if numbers fell below a given threshold. It is also worth noting that introducing mainly primiparous cows into the herd to maintain lactating cow numbers would decrease the average milk yield for the herd; therefore, the differences in milk yield observed herein would also be decreased. One strategy that high-producing herds with good reproductive performance can take is to extend the VWP (Arbel et al., 2001; Sørensen and Østergaard, 2003; Tenhagen et al., 2003) or shorten the dry period (Watters et al., 2008, 2009; Santschi et al., 2011).

\section{CONCLUSIONS}

Accuracy of ED and compliance with injections for the TAI protocol both affected reproductive performance; however, the effect of compliance was greater. Combining TAI with ED resulted in increased reproductive performance and profits compared with either TAI or ED alone within each level of accuracy or compliance with injections. This trend was not altered by milk price; however, percentage increase in profits for improving reproductive performance was much greater when milk price was low. The greatest improvement from combining TAI and ED was observed when compliance with injections was poor (85\%), even with low SR (40\%) and poor accuracy (85\%). Although combining TAI and ED increased reproductive performance and profits compared with either TAI or ED alone within each level of accuracy or compliance with injections, profits were not always increased with increased reproductive performance because of the decreased 
proportion of lactating cows in the herd and increased breeding costs. Therefore, when evaluated separately, the ED60-85 and ED60-95 models and the TAI-95 model performed better than the TAI-ED40-85 model despite having worse reproductive performance. Likewise, the ED60-95 model performed similarly to the TAI-ED40-95 model and better than the TAI-ED60-85 model. Herds can improve their profits by combining TAI and ED as reproductive management. However, if a herd can achieve high SR with high accuracy or have high compliance with injections, using only ED or TAI might be more profitable than trying to do both.

\section{ACKNOWLEDGMENTS}

The authors thank Jose Santos and Eduardo Ribeiro from the University of Florida, Department of Animal Sciences, and Julio Giordano from Cornell University, Department of Animal Science, for providing data for the estimation of the effect of AI upon accurate and inaccurate estrus detection on conception rate.

\section{REFERENCES}

Arbel, R., Y. Bigun, E. Ezra, H. Sturman, and D. Hojman. 2001. The effect of extended calving intervals in high-yielding lactating cows on milk production and profitability. J. Dairy Sci. 84:600-608.

Bicalho, R. C., K. N. Galvão, L. D. Warnick, and C. L. Guard. 2008. Stillbirth parturition reduces milk production in Holstein cows. Prev. Vet. Med. 84:112-120.

Brick, T. A., G. M. Schuenemann, S. Bas, J. B. Daniels, C. R. Pinto, D. M. Rings, and P. J. Rajala-Schultz. 2012. Effect of intrauterine dextrose or antibiotic therapy on reproductive performance of lactating dairy cows diagnosed with clinical endometritis. J. Dairy Sci. 95:1894-1905.

Britt, J. H. 1985. Enhanced reproduction and its economic implications. J. Dairy Sci. 68:1585-1592.

Burke, J. M., R. L. de la Sota, C. A. Risco, C. R. Staples, E. J. Schmitt, and W. W. Thatcher. 1996. Evaluation of timed insemination using a gonadotropin-releasing hormone agonist in lactating dairy cows. J. Dairy Sci. 79:1385-1393.

Caraviello, D. Z., K. A. Weigel, P. M. Fricke, M. C. Wiltbank, M. J. Florent, N. B. Cook, K. V. Nordlund, N. R. Zwald, and C. L. Rawson. 2006. Survey of management practices on reproductive performance of dairy cattle on large US commercial farms. J. Dairy Sci. 89:4723-4735.

Cerri, R. L., J. E. Santos, S. O. Juchem, K. N. Galvão, and R. C. Chebel. 2004. Timed artificial insemination with estradiol cypionate or insemination at estrus in high-producing dairy cows. J. Dairy Sci. 87:3704-3715.

De Vries, A. 2001. Statistical process control charts applied to dairy herd production. PhD Thesis. University of Minnesota, St. Paul.

De Vries, A. 2004. Economics of delayed replacement when cow performance is seasonal. J. Dairy Sci. 87:2947-2958.

De Vries, A. 2006. Economic value of pregnancy in dairy cattle. J. Dairy Sci. 89:3876-3885.

De Vries, A., M. B. Crane, J. A. Bartolome, P. Melendez, C. A. Risco, and L. F. Archbald. 2006. Economic comparison of timed artificial insemination and exogenous progesterone as treatments for ovarian cysts. J. Dairy Sci. 89:3028-3037.

Dechow, C. D., and R. C. Goodling. 2008. Mortality, culling by sixty days in milk, and production profiles in high- and low-survival Pennsylvania herds. J. Dairy Sci. 91:4630-4639.
El-Zarkouny, S. Z., J. A. Cartmill, B. A. Hensley, and J. S. Stevenson. 2004. Pregnancy in dairy cows after synchronized ovulation regimens with or without presynchronization and progesterone. J. Dairy Sci. 87:1024-1037.

Galvão, K. N., and J. E. Santos. 2010. Factors affecting synchronization and conception rate after the Ovsynch protocol in lactating Holstein cows. Reprod. Domest. Anim. 45:439-446.

Galvão, K. N., J. E. Santos, R. L. Cerri, R. C. Chebel, H. M. Rutigliano, R. G. Bruno, and R. C. Bicalho. 2007. Evaluation of methods of resynchronization for insemination in cows of unknown pregnancy status. J. Dairy Sci. 90:4240-4252.

Galvão, K. N., J. E. Santos, S. O. Juchem, R. L. Cerri, A. C. Coscioni, and M. Villaseñor. 2004. Effect of addition of a progesterone intravaginal insert to a timed insemination protocol using estradiol cypionate on ovulation rate, pregnancy rate, and late embryonic loss in lactating dairy cows. J. Anim. Sci. 82:3508-3517.

Giordano, J. O., P. M. Fricke, M. C. Wiltbank, and V. E. Cabrera. 2011. An economic decision-making support system for selection of reproductive management programs on dairy farms. J. Dairy Sci. 94:6216-6232.

Giordano, J. O., J. N. Guenther, G. Lopes Jr., and P. M. Fricke. 2012a. Changes in serum pregnancy-associated glycoprotein, pregnancyspecific protein $\mathrm{B}$, and progesterone concentrations before and after induction of pregnancy loss in lactating dairy cows. J. Dairy Sci. 95:683-697.

Giordano, J. O., M. C. Wiltbank, J. N. Guenther, R. Pawlisch, S. Bas, A. P. Cunha, and P. M. Fricke. 2012b. Increased fertility in lactating dairy cows resynchronized with Double-Ovsynch compared with Ovsynch initiated $32 \mathrm{~d}$ after timed artificial insemination. J. Dairy Sci. 95:639-653

Heersche, G., Jr., and R. L. Nebel. 1994. Measuring efficiency and accuracy of detection of estrus. J. Dairy Sci. 77:2754-2761.

Hertl, J. A., Y. T. Gröhn, J. D. Leach, D. Bar, G. J. Bennett, R. N. González, B. J. Rauch, F. L. Welcome, L. W. Tauer, and Y. H. Schukken. 2010. Effects of clinical mastitis caused by grampositive and gram-negative bacteria and other organisms on the probability of conception in New York State Holstein dairy cows. J. Dairy Sci. 93:1551-1560.

Inchaisri, C., R. Jorritsma, P. L. Vos, G. C. van der Weijden, and H. Hogeveen. 2010. Economic consequences of reproductive performance in dairy cattle. Theriogenology 74:835-846.

Kastelic, J. P., and O. J. Ginther. 1989. Fate of conceptus and corpus luteum after induced embryonic loss in heifers. J. Am. Vet. Med. Assoc. 194:922-928.

Lima, F. S., A. De Vries, C. A. Risco, J. E. Santos, and W. W. Thatcher. 2010. Economic comparison of natural service and timed artificial insemination breeding programs in dairy cattle. J. Dairy Sci. 93:4404-4413.

Marsh, T. G., R. S. Morris, and A. A. Dijkhuizen. 1985. An economic comparison of four culling decision rules for reproductive failure in the US dairy herds using Dairy ORACLE. J. Dairy Sci. 70:1274-1280

Meadows, C., P. J. Rajala-Schultz, and G. S. Frazer. 2005. A spreadsheet-based model demonstrating the nonuniform economic effects of varying reproductive performance in Ohio dairy herds. J. Dairy Sci. 88:1244-1254.

McClure, A. M. 2007. Experiences of a veterinary reproductive management service to achieve reproductive success in large herds. Dairy Cattle Reproduction Council (DCRC) annual meeting. DCRC, Denver, CO.

Moreira, F., C. Orlandi, C. A. Risco, R. Mattos, F. Lopes, and W. W. Thatcher. 2001. Effects of presynchronization and bovine somatotropin on pregnancy rates to a timed artificial insemination protocol in lactating dairy cows. J. Dairy Sci. 84:1646-1659.

Navanukraw, C., D. A. Redmer, L. P. Reynolds, J. D. Kirsch, A. T. Grazul-Bilska, and P. M. Fricke. 2004. A modified presynchronization protocol improves fertility to timed artificial insemination in lactating dairy cows. J. Dairy Sci. 87:1551-1557.

Norman, H. D., J. R. Wright, S. M. Hubbard, R. H. Miller, and J. L. Hutchison. 2009. Reproductive status of Holstein and Jersey cows in the United States. J. Dairy Sci. 92:3517-3528. 
NRC. 2001. Nutrient Requirements of Dairy Cattle. 7th rev. ed. Natl. Acad. Sci. Washington, DC

Overton, M. W. 2005. Cost comparison of natural service sires and artificial insemination for dairy cattle reproductive management. Theriogenology 64:589-602.

Parmigiani, E., L. Ball, D. Lefever, G. Rupp, and G. Seidel Jr.. 1978. Elective termination of pregnancy in cattle by manual abortion. Theriogenology 10:283-290.

Pinedo, P. J., and A. De Vries. 2010. Effect of days to conception in the previous lactation on the risk of death and live culling around calving. J. Dairy Sci. 93:968-977.

Plaizier, J. C. B., G. J. King, J. C. M. Dekkers, and K. Lissemore. 1997. Estimation of economic values of indices for reproductive performance in dairy herds using computer simulation. J. Dairy Sci. 80:2775-2783.

Pursley, J. R., M. O. Mee, and M. C. Wiltbank. 1995. Sychronization of ovulation in dairy cows using $\mathrm{PGF}_{2 \mathrm{a}}$ and $\mathrm{GnRH}$. Theriogenology 44:915-923.

Pursley, J. R., M. R. Kosorok, and M. C. Wiltbank. 1997a. Reproductive management of lactating dairy cows using synchronization of ovulation. J. Dairy Sci. 80:301-306.

Pursley, J. R., M. C. Wiltbank, J. S. Stevenson, J. S. Ottobre, H. A Garverick, and L. L. Anderson. 1997b. Pregnancy rates per artificial insemination for cows and heifers inseminated at a synchronized ovulation or synchronized estrus. J. Dairy Sci. 80:295-300.

Ribeiro, E. S., R. S. Bisinotto, M. G. Favoreto, L. T. Martins, R. L. Cerri, F. T. Silvestre, L. F. Greco, W. W. Thatcher, and J. E. Santos. 2012. Fertility in dairy cows following presynchronization and administering twice the luteolytic dose of prostaglandin $\mathrm{F}(2 \alpha)$ as one or two injections in the 5-day timed artificial insemination protocol. Theriogenology 78:273-284.

Santos, J. E. P., W. W. Thatcher, R. C. Chebel, R. L. A. Cerri, and K. N. Galvão. 2004. The effect of embryonic death rates in cattle on the efficacy of estrus synchronization programs. Anim. Reprod. Sci. 82-83:513-535.

Santos, J. E., C. D. Narciso, F. Rivera, W. W. Thatcher, and R. C. Chebel. 2010. Effect of reducing the period of follicle dominance in a timed artificial insemination protocol on reproduction of dairy cows. J. Dairy Sci. 93:2976-2988.

Santschi, D. E., D. M. Lefebvre, R. I. Cue, C. L. Girard, and D. Pellerin. 2011. Complete-lactation milk and component yields follow- ing a short (35-d) or a conventional (60-d) dry period management strategy in commercial Holstein herds. J. Dairy Sci. 94:2302-2311.

Schuenemann, G. M., S. Bas, E. Gordon, and J. Workman. 2011. III. Dairy calving management: Assessment of a comprehensive program for dairy personnel. J. Dairy Sci. 94 (Suppl. 1):483. (Abstr.) Sørensen, J. T., E. S. Kristensen, and I. Thysen. 1992. A stochastic model simulating the dairy herd on a PC. Agric. Syst. 39:177-200.

Sørensen, J. T., and S. Østergaard. 2003. Economic consequences of postponed first insemination of cows in a dairy cattle herd. Livest. Prod. Sci. 79:145-153.

Tenhagen, B. A., M. Drillich, R. Surholt, and W. Heuwieser. 2004 Comparison of timed AI after synchronized ovulation to AI at estrus: Reproductive and economic considerations. J. Dairy Sci 87:85-94.

Tenhagen, B. A., C. Vogel, M. Drillich, G. Thiele, and W. Heuwieser. 2003. Influence of stage of lactation and milk production on conception rates after timed artificial insemination following Ovsynch. Theriogenology 60:1527-1537.

USDA. 2009. Dairy 2007, Part IV: Reference of Dairy Cattle Health and Management Practices in the United States. Accessed mon/ day/year. Accessed January 29, 2013. http://www.aphis.usda. gov/animal_health/nahms/dairy/downloads/_dairy07/Dairy07_ dr_PartIV.pdf.

van Arendonk, J. A. M. 1985. Studies on the replacement policies in dairy cattle. II. Optimum policy and influence of changes in production and prices. Livest. Prod. Sci. 13:101-121.

Watters, R. D., J. N. Guenther, A. E. Brickner, R. R. Rastani, P. M. Crump, P. W. Clark, and R. R. Grummer. 2008. Effects of dry period length on milk production and health of dairy cattle. J. Dairy Sci. 91:2595-2603.

Watters, R. D., M. C. Wiltbank, J. N. Guenther, A. E. Brickner, R. R. Rastani, P. M. Fricke, and R. R. Grummer. 2009. Effect of dry period length on reproduction during the subsequent lactation. J. Dairy Sci. 92:3081-3090.

Wilensky, U. 1999. NetLogo. Center for Connected Learning and Computer-Based Modeling. Northwestern University, Evanston, IL. http://ccl.northwestern.edu/netlogo/.

Wood, P. D. P. 1967. Algebraic model of the lactation curve in cattle. Nature 216:164-165. 


\section{APPENDIX}

Initialization of model parameters (e.g. mean estrus duration, estrus detection (ED) accuracy, etc.)

Definition of variables holding information about daily totals (e.g. number of Al, number of pregnant cows, cost of Al, etc.)

Creation of individual cows and initialization of their attributes (e.g., age, weight, reproductive status, etc.)

For each day in the simulation

Daily totals are initialized as zero

For each individual cow the following functions are evaluated

Estrus function

Determines next estrus days for individual

Determines if cow is in estrus at this particular day

Estrus detection

If the cow is in estrus, and past the voluntary waiting period (e.g. 50 DIM for ED model) but $\leq 366$

DIM, then estrus is detected with a given probability (e.g. 40 or $60 \%$ )

Cow is artificially inseminated

Conception occurs with given probability (this probability varies depending on Al protocol, accuracy

of ED, and number of services)

Cow reproductive status is updated to "pregnant"

Other related individual attributes are updated (e.g. number of service)

Daily counters are updated (e.g., total number of Al)

Synchronization protocol (if applies)

If corresponds (cow is open, milking days appropriate, etc.) the cow is assigned to the

corresponding injection for the synchronization protocol

The corresponding injection is updated as "successful" with a given compliance probability

Cow is artificially inseminated if the cow is at the end of the protocol.

Conception occurs with given probability (this probability varies depending on Al protocol, compliance with protocol, and number of services)

Cow reproductive status is updated if corresponds

Other related individual attributes are updated (e.g., number of service, injection received, etc.)

Daily counters are updated (e.g., total number of Al, number of injections)

Abortion

If cow is pregnant abortion is determined with a given probability (this probability depends on the days pregnant)

The reproductive status of the cow is updated to "not pregnant"

A new estrus date is determined

Other related individual attributes are updated (e.g., number of abortion since last calving event)

Diagnostic

Diagnostic takes place 32 days after $\mathrm{Al}$ in cows that have not been resinseminated.

Daily counters are updated (e.g., total number of pregnancy checks)

Dry Pregnant

If the cow has being pregnant for 220 days its milking status is updated to "dry"

Calving

If the cow has being pregnant for 280 days its status is updated to "not pregnant" and "milking"

Other related individual attributes are updated (e.g., number of lactations)

Daily number of calves is updated

Replace Cow

Determines if a cow is to be replaced depending on pregnancy status (i.e. not pregnant) and days in

milk (i.e. 450) or based on income over cost of production (income from milk sales is less than

feeding cost plus other costs)

Daily counters are updated (e.g., total number replaced cows)

Death

The cow is eliminated from the simulation with a given probability (daily mortality probability)

Updated Cows

Age of the cow is updated (one day older)

Food intake is calculated

If the cow is milking, its production is calculated

Other related individual attributes are updated (e.g., number of days pregnant, number of days

milking, etc.)

Daily counters are updated (e.g., total number replaced cows)

Evaluate next cow

\section{Buy Cows \\ A number of \\ Daily Economic Calculations \\ Daily cost variables are updated \\ Simulate next day}

Figure A1. Pseudo-code showing model structure and order of events using the Netlogo modeling environment (http://ccl.northwestern. edu/netlogo) 